\title{
Determining pediatric asthma control in real-life: Comparison of Pediatric Asthma Control Test, Asthma Control Test, Fractional exhaled nitric oxide, Pediatric Asthma Quality of Life Questionnaire and Lung function with GINA criteria
}

\author{
Aysegul Akan ${ }^{1}$, Emine Misirlioglu ${ }^{2}$, Ersoy Civelek ${ }^{3}$, and Can Kocabas ${ }^{4}$ \\ ${ }^{1}$ Health Sciences University, Trabzon Kanuni Research and Education Hospital \\ ${ }^{2}$ Health Sciences University, Ankara City Hospital \\ ${ }^{3}$ Ankara Children's Hematology Oncology Education and Research Hospital \\ ${ }^{4}$ Hacettepe University Faculty of Medicine
}

May 14, 2020

\begin{abstract}
Background Guidelines as Global Initiative for Asthma(GINA) recommend disease control as the mainstay of asthma management. The performance of the tools assessing in asthma control is challenging in real-life. Methods Children and adolescents with asthma followed at a tertiary research hospital were enrolled in the study after evaluation of adherence to treatment. Asthma Control Test(ACT)/Pediatric Asthma Control Test(PACT), Pediatric Asthma Quality of Life Quesstionnaire(PAQLQ), fractional exhaled nitric oxide(FeNO) and lung function were evaluated. Patients were examined by asthma specialists blinded to the results of the tools and their control status were evaluated based on GINA. Results The median age(interquartile range,IQR) of the patients was 10.7(8.4-12.9) years, $57.9 \%$ were boys. Of 228 children, $84.2 \%, 9.6 \%$ and $6.1 \%$ had "well-controlled", "partially-controlled" and "uncontrolled" asthma, respectively. The patients with "partially-controlled " and "uncontrolled" asthma were grouped as "not well-controlled". The cut-off levels were 22, 21 and 5.9 for PACT, ACT and PAQLQ for determining "well-controlled" asthma $(\mathrm{p}<0.001)$. With these cut-off values, ACT had the higher compatibility with GINA than PACT and PAQLQ $(x=0.221,0.473$ and 0.150 , respectively, $\mathrm{p}<0.001)$. Correctly classified patients with PACT, ACT and PALQLQ based on GINA with these cut-off levels were 93(64.1\%),63(75.9\%) and 139(62.9\%), respectively. FeNO and lung function were unsuccessful at revealing control status according to GINA. Conclusion ACT is better than PACT at compatibility with GINA. Probably, it is because older children have a longer recall period than younger ones. It would be better to use these tools for each patient by comparing their own scores in real-life, instead of cut-off values.
\end{abstract}

\section{INTRODUCTION}

Asthma is one of the most common chronic diseases in childhood with an increasing prevalence worldwide ${ }^{1}$. It is a heterogeneous inflammatory disease of the airways which is characterized by recurrent wheezing episodes, cough, dyspnea and chest tightness during daily activity and sleep. ${ }^{1}$ Childhood asthma has a wide variation in age of onset, type and frequency of respiratory symptoms, exacerbations, triggers, lung functions, comorbidities and underlying inflammatory patterns. Therefore, an individualized approach may be needed to improve asthma outcome and reduce future risks as exacerbations and decline in lung function and side effects of therapy. ${ }^{2}$

Since 2000s, international asthma guidelines, such as the Global Initiative for Asthma(GINA) ${ }^{1}$ and the National Asthma Education and Prevention Program(NAEPP) ${ }^{3}$, recommend to achieve "control" in asthma 
which means efective management of the clinical characteristics of the disease. These are symptoms, nocturnal awakening, reliever use, activity limitation and lung function. The level of asthma control is the extent to which the manifestations of asthma can be observed in the patient, or have been reduced or removed by treatment. ${ }^{1}$ Although they are on controller therapy, a considerable proportion of children have suboptimal asthma control. ${ }^{4}$ This means despite regular treatment guidelines, numerous children suffer from sleep disturbances, exercise intolerance and need unscheduled health care visits and even hospitalization that results in school absenteeism. ${ }^{5}$ Hence, there is a need for validated and noninvasive instruments to assess asthma control in children providing compatible results with the gold standard guidelines.

There are several validated tools developed to guide asthma specialists to determine asthma control and modify therapy. Asthma Control Test(ACT) and Pediatric Asthma Control Test(PACT) are the numeric tools for assessing symptom control recommended by GINA. ${ }^{1}$ Both are validated and reliable tests used worlwide. Neverthless, the compatibility and cut-off values of ACT/PACT which reflect the patients' and/or caregivers' perception of asthma symptoms according to GINA based control measurement for children are challenging. ${ }^{6-10}$

Although lung function does not correlate strongly with asthma symptoms in children, forced expiratory volume in 1 second $\left(\mathrm{FEV}_{1}\right)$ is requested to be used by GINA, because of the relation with asthma control and future exacerbations. ${ }^{1}$ So, it should be used while regular asthma follow-up as a component of evaluation of asthma control based on GINA criteria. ${ }^{1}$

Fractional exhaled nitric oxide(FeNO) is an inflammatory marker of airways which is noninvasive, reproducible and relatively easy to use in patients. ${ }^{11}$ High FeNO at the time of loss of asthma control and decrease of FeNO after treatment with corticosteroids imply that FeNO may be useful not only to predict asthma excerbations, but also be helpful in monitoring the response to treatment. ${ }^{12}$ This inspired many researchers that FeNO could be utilized as a tool for assessment of asthma control, but its use for this purpose needs to be further clarified particularly in children. ${ }^{11}$

Pediatric Asthma Quality of Life Questionnaire(PAQLQ) was developed as a self-administered test by Juniper et al in 1996. ${ }^{13}$ It comprises of 3 domains as symptoms, emotional functions and activity limitation. Children and adolescents with poor asthma control will have more frequent symptoms, medication use and activity limitation which means impairement of health related quality of life. ${ }^{14,}{ }^{15}$ And, this can be detected by PAQLQ which is invented for asthmatic children specifically.

Therefore, assessing asthma control in childhood is a crucial step in asthma management as in adults. The relationship of different tools with GINA criteria in assessing asthma control was investigated in the literature. Most studies manifested different results, beacuse they were performed in different countries and care settings, with different study plans and methods. Neverthless, clinicans working with children need to know which tool can be confidentially used to assess asthma control properly in real-world settings. Based on this need, we planned this study to evaluate the compatibility of the common used tools for assessing asthma control(ACT, PACT, PAQLQ, FeNO, lung function) with GINA criteria in daily clinical practice.

\section{METHODS}

\section{Study population}

Between January 2012 and January 2014, the patients with asthma, aged 6-18 years old, were invited to the study while their routine asthma follow-up at the outpatient clinic of Pediatric Allergy Department of a tertiary research and training hospital. The must inclusion criteria was to have physician diagnosed asthma based on criteria recommended by the GINAand the US National Asthma Education and Prevention Program. ${ }^{1,3}$ The others were to be adherent to their asthma treatment, able to perform FeNO and spirometry measurements properly according to the guidelines. Children were excluded if they did not meet all inclusion criteria or had comorbid diseases other than allergic diseases, if they were having an acute attack or respiratory infection which were unfavorable for FeNO and spirometry tests. The study was approved by the Institutional Review Board. Parent/caregiver provided informed consent and writtten assent was taken 
from children older than 6 years old.

\section{Study design}

Before the recruitment, patients were evaluated for their adherence to treatment. If the patients and caregivers were using their treatment properly with right technique, they were evaluated for the control status of asthma and needed therapy. This first evaluation visit was also a preparation and adaptation for filling the forms of ACT/PACT, PAQLQ and measurement of FeNO and lung function. The patients completed this visit successfully were enrolled in the study. A diary was given to each patient in order to note their symptoms and the controller/rescue treatment that they received. They were called for control visit and tests 4 weeks later.

The next visit was recorded as the main visit of the study. At the visit, children/caregivers completed ACT or PACT according to their age group and PAQLQ. Second step composed of FeNO measurement and spirometric evaluation, respectively. Then, patients were evaluated by the same pediatric asthma specialists in a blinded way to PACT/ACT scores and FeNO results, who determined the "control status" of the patients and adjusted the therapy according to the GINA guidelines via the diary filled by them, in order to achieve or maintain a status of "controlled asthma". Descriptive and clinical features were learnt from the caregivers and the medical records.

\section{Assessment of asthma control}

The GINA guidelines ${ }^{1}$ recommend to evaluate daytime symptoms, nocturnal symptoms, need for reliever therapy, limitation of physical activities, lung function and assessment of future risk in order to determine control status. Based on the parameters defined by the GINA guidelines, patients were grouped as having "well-controlled", "partly controlled" and "uncontrolled" asthma for the previous 4 weeks. "Partly controlled" and "uncontrolled" group were collected as "not well-controlled". So, the analyses were performed for these two groups of "well-controlled" and "not well-controlled" asthma. ${ }^{6}$

\section{Skin Prick Test}

Skin prick tests(SPT) were performed all study group. It was performed on the volar aspect of the forearm. Common inhaled allergens(house dust mites, cockroach, animal danders, fungi and mixed grass and tree pollens) were allergens. All SPTs were performed using commercial extracts (Laboratoire Stallergenes, France). Temoline was used as negative control and histamine $(10 \mathrm{mg} / \mathrm{ml})$ as positive control. Reaction was evaluated 15-20 minutes after allergens were applied. Test result was defined as positive if the wheal diameter of test was at least $3 \mathrm{~mm}$ greater than that of the negative control. ${ }^{16}$

\section{Pediatric Asthma Control Test(PACT) and Asthma Control Test(ACT)}

The participants younger than 12 years-old were given PACT. The validated version of the tests for Turkish language was administered. ${ }^{17}, 18$ The PACT composed of two parts. Children and their parents answered their respective parts and the sum of their scores formed the final score. The maximum total score for PACT is 27 which reflects total control in asthma. The ACT composed of 5 questions answered only by the patients older than 12 years-old. The maximum total score for ACT is 25 that means totally controled asthma. The questions assess asthma symptoms(daytime and nocturnal), use of rescue medications, and the effect of asthma on daily functioning. A score of $<19$ for both tests indicates uncontrolled asthma. ${ }^{19,} 20$

\section{Pediatric Asthma Quality of Life Questionnaire(PAQLQ)}

The PAQLQ was a self-administered test developed by Juniper et al and translated to many languages. ${ }^{13}$ The validated Turkish version of PAQLQ was used. ${ }^{21}$ It is a disease specific quality of life questionnaire consisting of 23 items and 3 domains. These domains are symptoms(10 items), emotional functions(8 items) and activity limitations(5 items). Each of the items have seven-point response Likert type scales, ranging from 1 (severe impairement) to 7 (no impairement). The final score is obtained by the aritmetic mean of all items, so all domains weighed the result equally. 


\section{FeNO measurement}

FeNO was measured online by using the single-breath technique with a portable analyzer(NIOX-MINO, Aerocrine, Stockholm, Sweden) according to guidelinesand expressed as parts per billion. ${ }^{12,}{ }^{22}$ Measurements were performed before lung function tests. After inhalation of nitric oxide-free air for total lung capacity, the measurement was performed while the patient exhaled at a constant flow rate of $50 \mathrm{ml} / \mathrm{s}$. In the American Thoracic Society guideline, FeNO mesurements of children with asthma were recommended to be evaluated with the cut-off levels of $<20 \mathrm{ppb}$ and $>35 \mathrm{ppb}$, which is probably to mean less and more likely for eosinophilic inflammation and corticosteroid response. ${ }^{12}$

\section{Lung function}

All patients underwent lung function tests by using Spirolab II system(Medical International Research, Rome, Italy). It was performed by a trained operatör, and the equipment was calibrated daily. Measured parameters were the prebronchodilator forced expiratory volume in 1st second(FEV1), the forced vital capacity(FVC), the FEV1 to FVC ratio(FEV1/FVC) and the forced expiratory flow between $25 \%$ and $75 \%$ of vital capacity $\left(\mathrm{FEF}_{25 \%-75 \%}\right)$. Results were reported as percentage of the predicted value according to references. ${ }^{23}$

\section{Statistical analysis}

Results were expressed as median and interquartile range(IQR) or proportions as required. While normality tests were negative, the comparison of continuous variables(PACT, ACT, PAQLQ, FeNO, FEV1, FVC, FEV1/FVC, $\mathrm{FEF}_{25 \%-75 \%}$ ) were performed using Mann-Whitney U test. The percentages of these variables were compared using qhi-square test. Correlation between tests were investigated by Spearman correlation test. The diagnostic value of the PACT, ACT and PAQLQ to detect "well controlled" asthma as defined by GINA was determined by calculation of area under the curve(AUC) of receiver operating characteristic(ROC) curves. The compatibility of the tests with GINA criteria were assessed by kappa test $(\varkappa)$. Statistical significance was defined if $\mathrm{p}<0.05$. Analyses were performed using SPSS statistical software, version 20.0(SPSS Inc, Chicago, Illinois).

\section{RESULTS}

Totally, 249 children with asthma were enrolled. Twelve of them were excluded because three of them didn't come the control visit to perform the tests, five of them had acute respiratory infection that may affect FeNO measurement and four of them didn't use their controller therapy appropriately. Finally, 228 patients(median age[interquartile range, IQR] 10.7[8.4-12.9] years) completed the study, of whom 132(57.9\%) were boys. Study population performed 145 PACT, 83 ACT and 221 PAQLQ tests. Asthma follow-up duration was similar for older $(>12 \mathrm{yrs})$ and younger patients $(<12 \mathrm{yrs})(\mathrm{p}=0.44)$. All of the patients underwent FeNO and lung function .

For the whole study population, the medians(IQR) were 22(18-25) for PACT; 22(18-24) for ACT; 5.9(4.9-6.6) for PAQLQ total; 5.2(4.2-6.4) PAQLQ symptoms domain; 6.0(5.1-6.7) PAQLQ activities domain; 6.2(5.26.9) for PAQLQ emotions domain; 19(14-27) for FeNO; 93(87-103) for $\mathrm{FEV}_{1}$ (expected\%); 0.98(0.93-1.05) for $\mathrm{FEV}_{1} / \mathrm{FVC}$ (ratio) and 89(79-112) for $\mathrm{FEF}_{25-75}$ (expected\%). Total PAQLQ and symptoms domain were significantly higher for participants $<12$ years old than those $>12$ years old(PAQLQ total: median(IQR) for $<12$ yrs 6.1(5.2-6.6), $>12$ yrs 5.6(4.4-6.5), $\mathrm{p}=0.018$; symptoms domain: median[IQR] for $<12$ yrs 5.4(4.5-6.6), $>12$ yrs 5.0(3.7-6.1), $\mathrm{p}=0.022$ ). PAQLQ activities and emotions domains were similar for age groups $(\mathrm{p}=0.092$ and 0.242 , respectively). Also, FeNO was significantly higher for the older age group(median[IQR] for $<12$ yrs 18(14-27), $>12$ yrs 21(16-32), $\mathrm{p}=0.023)$. There were no difference for lung function between age groups $(\mathrm{p}>0.05)$.

According to GINA criteria, $84.2 \%$ of the study population(n=192) had "well-controlled" asthma, while $9.6 \%$ and $6.1 \%$ of them were identified as "partially-controlled" and "uncontrolled" asthma. 15.7\%of patients had "not-well controlled" asthma. Older patients $(>12 \mathrm{yrs})$ had more frequently "not well-controlled" asthma than younger ones $(<12$ yrs $)(22.9 \%[19]$ versus $11.7 \%[17]$, respectively, $\mathrm{p}=0.026)$. Female and older patients had more frequently "not well-controlled" asthma defined by GINA criteria than males and younger 
ones( $\mathrm{p}=0.012$ and 0.005 , respectively). Besides, atopic patients had more frequently "well-controlled" asthma according to GINA criteria than those without atopy $(\mathrm{p}=0.021)$. The score of PACT, ACT and PAQLQ were higher for the patients with "well-controlled asthma" $(\mathrm{p}<0.001)$, whereas medians of FeNO and lung function of the groups were not different(Table 1).

The only significant correlation was between PAQLQ and PACT or ACT $(r=0.658$ and $r=0.789, p<0.001$, respectively). FeNO and lung function had no correlation with neither each other nor other tests $(\mathrm{p}>0.05)$ (data not shown).

Comparing PACT to GINA criteria for "well controlled asthma" resulted in an AUC of the ROC curve of $0.79(95 \%$ CI $0.70-0.88, \mathrm{p}<0.001)$. The cut-off level of 21.5 has the highest sensitivity and specifity $(0.609$ and 0.882 , respectively). As a result, the cut-off level of 22(PACT $>22$ for "well controlled asthma") provided the highest compatibility of PACT with GINA (correctly classified 93[64.1\%], $x=0.221, \mathrm{p}<0.001$ ). Likewise, the ROC curve analyses of ACT resulted in an AUC of $0.86(95 \% \mathrm{CI} 0.76-0.96, \mathrm{p}<0.001)$. The cut-off level of 20.5 has the highest sensitivity and specifity(0.719 and 0.895 , respectively). Ultimately, the cut-off level of 21(ACT $>21$ for "well controlled asthma") provided the highest compatibility of ACT with GINA (correctly classified $63[75.9 \%], x=0.473, \mathrm{p}<0.001$ ). By the same way, the ROC curve analyses of PAQLQ revealed an AUC of $0.76(95 \%$ CI $0.67-0.84, \mathrm{p}<0.001)$. The cut-off level of 5.85 has the highest sensitivity and specifity $(0.591$ and 0.828 , respectively). Finally, the cut-off level of 5.9(PAQLQ $>5.9$ "well controlled asthma") provided the highest compatibility of PAQLQ with GINA (correctly classified 139[62.9\%], $\chi=0.150$, $\mathrm{p}<0.001$ )(Table 2). The performance of different cut-off values of PACT and ACT were shown in table 3 and 4. We also assessed the predictive value of FeNO to predict "not-well controlled" asthma, which was poor $(\mathrm{AUC}=0.45, \mathrm{p}=0.75$ ) (data not shown). PAQLQ had higher agreement with GINA for the patients $>$ 12 years old than those younger than 12 yeras old $(\varkappa=0.326, \mathrm{p}<0.001$ and $\chi=0.151, \mathrm{p}=0.014$, respectively). PAQLQ had stronger correlation with ACT $(r=0.789, \mathrm{p}<0.001)$ than $\operatorname{PACT}(\mathrm{r}=0.658, \mathrm{p}<0.001)$.

\section{DISCUSSION}

In this prospective study, the compatibility of the tools such as PACT, ACT, FeNO, PALQLQ and lung function with GINA criteria were evaluated in children. According to GINA criteria, $84.2 \%$ of the patients had "well-controlled" asthma.

FeNO and lung function were unsuccessful at revealing control status according to GINA criteria(Table 1, 2). PACT/ACT and PAQLQ were demonstrated to be able to determine "well controlled asthma" to some extent of consistency with GINA criteria(Table 2). The best consistency with the highest sum of sensitivity and specifity were obtained with the cut-off levels of 22 for PACT, 21 for ACT and 5.9 for PAQLQ(Table 2). Neverthless, there were only fair agreement with the kappa value of 0.221 and 0.150 for PACT and PAQLQ, respectively $(\mathrm{p}<0.001)$. Besides, moderate agreement was obtained between ACT and $\operatorname{GINA}(x=0.473, \mathrm{p}<0.001)$. Correctly classified patients with PACT, ACT and PALQLQ according to GINA were $93(64.1 \%), 63(75.9 \%)$ and $139(62.9 \%)$, respectively. Ultimately, ACT gives the best result for assessing asthma control in children $>12$ year-old. Also, PAQLQ gives better compatibility for asthma control in children $>12$ years old than those younger $<12$ years old.

In our study, girls with older age have more frequently "not well-controlled" asthma. This may be due to the adverse impact of sex hormones on the control status of asthma which is a particular problem for female adult patients. Frequency of allergic sensitisation is also lower in the group of "not well-controlled" asthma. All these may be a suggestion of the hypothesis that gender disparity in asthma control starts at puberty approximately at the age of 10 years. $^{24}$

Although there is no approved or validated gold standard for determining asthma control, GINA criteria are accepted to be used such as worldwide in daily practice. ${ }^{5,}{ }^{25}$ PACT and ACT are some of the tools validated and mostly used in clinical practice to assess asthma control in children. Although the studies comparing the compatibility of them and GINA criteria for the assessment of asthma control had challenging results. ${ }^{6-10}$

In the study of Koolen et al, they compared PACT and ACT with GINA criteria in assessing asthma control 
of children with similar study design. ${ }^{10}$ They found an AUC of ROC curve analyses for PACT 0.89 and ACT 0.92 which were higher than our study(0.79 and 0.86 in our study, respectively). In their study, the cut-off value with the highest sum of sensitivity and specifity for ACT was $<20$ for uncontrolled asthma, which is the same as our study. The cut-off value for PACT in their study was $<22$, which is one point higher than that in our study $(<21)$. The sensitivity and specifity of both PACT and ACT(sensitivity $82 \%$ and $76 \%$; specifity $85 \%$ and $96 \%$, respectively) with the calculated cut-off values were higher than our study(sensitivity $60.9 \%$ and $71.9 \%$; specifity $88.2 \%$ and $89.5 \%$, respectively). This may be due to that Koolen et al(n=145) had more patients with uncontrolled(13.1\%) and partly controlled asthma(33.8\%) than those in our study $(6.1 \%$ and $9.6 \%$, respectively). Another reason may be patients with uncontrolled and partly controlled asthma were evaluated together in the "not-well controlled" asthma group in our study.

In another study with similar design, Voorend-van Bergen et al $(\mathrm{n}=228)$ found the same best cut-off value for $\operatorname{PACT}(>22)$ for "well-controlled" asthma with respect to GINA criteria. ${ }^{8}$ They proposed to determine "wellcontrolled" asthma which is the primary goal of clinical asthma management according to GINA criteria. Their AUC for $\operatorname{PACT}(0.81)$ was also similar to our results(0.79). On the other hand, their best cut-off value for $\mathrm{ACT}(>23, \mathrm{AUC}=0.91)$ was higher than $\operatorname{ours}(>21, \mathrm{AUC}=0.86)$.

In a recent study, Deschildre et al compared PACT performance of assessing asthma control with respect to GINA crtieria. ${ }^{7}$ Also, they grouped asthma level of patients as well controlled and not controlled(partially controlled or uncontrolled), as we did in our study. Using ROC curve analyses, they found the same cut-off value for $\operatorname{PACT}(<21$, for "not controlled" asthma) with a higher sensitivity $(76 \%)$, but lower specifity $(81.5 \%)$ than those found in our study $(60.9 \%$ and $88.2 \%$, respectively). However, the most important difference from our study is that the rate of "not controlled" asthma in their study $(76.5 \%)$ was much higher than that in our $\operatorname{study}(15.7 \%) .^{7}$

As in the study of Voorend-van Bergen et al, FeNO was not difference between the control groups of asthma as in our study. ${ }^{8}$ As similar to earlier studies, we found no correlation between asthma control scores, GINA criteria and $\mathrm{FeNO}$ or $\mathrm{FEV}_{1}{ }^{26-28}$. Symptoms, lung function and airway inflammation represent different domains of asthma phenotype and show poor agreement ${ }^{8}$. Many children with uncontrolled asthma have normal lung functions between exacerbations ${ }^{1}$. A low $\mathrm{FEV}_{1}$ percent predicted, particularly if it is $<60 \%$, identifies patients at risk of future asthma exacerbations independent of symptom levels ${ }^{1}$. If symptoms are few despite low $\mathrm{FEV}_{1}$ \%predicted, limitation of lifestyle or poor perception of airflow limitation should be considered that would be a marker of untreated airway inflammation. ${ }^{29,} 30$ In our study, none of the participants had $\mathrm{FEV}_{1}<60 \%$. Besides, there were no difference for $\mathrm{FEV}_{1}$ (expected \%), $\mathrm{FEV}_{1} / \mathrm{FVC}$ (ratio) and $\mathrm{FEF}_{25-75}$ (expected \%) between control groups and no compatibility with GINA criteria(Tabel 1 and 2).

In our study, ACT had better results for agreement and compatibility with GINA criteria than PACT. This may be due to that older children replies ACT and they had better perception of symptoms and longer recall period than children younger than 12 years old who replies PACT with their parents. Parents have a longer recall period than children, who may recall only the last few days ${ }^{1}$. The fact that younger children would be more frequently asymptomatic except exacerbations may have an additional contribution to this result. In accordance, the correlation of PAQLQ and ACT was stronger than that of PAQLQ and PACT in our study. Voorend-van Bergen et al had similar results for this correlation ${ }^{8}$. Additionally, PAQLQ had higher agreement with GINA criteria in children $>12$ years old than those of younger ones in our study $(x=0.326, \mathrm{p}<0.001$ and $\chi=0.151, \mathrm{p}=0.014$, respectively). There are several studies demonstrated the correlation between PAQLQ and ACT/PACT ${ }^{31-34}$. However, to the best of our knowledge, this is the first study to achieve a cut-off value for PAQLQ that has fair compatibility with GINA criteria.

The most important limitation of our study was lower number of patients with uncontrolled and partly controlled asthma. This may be a consequence of the study design that firstly the control status of asthma was evaluated, treatment adherence and inhaler technique were adjusted if needed. Four weeks later, patients were called for the main visit at which the adherence and technique of treatment was better than the first visit(data not shown). As a natural consequence, asthma control was better at the main visit. Besides, this was a real-world study which would provide more true information from daily clinical practice. Real- 
world studies presently start to become cause of choice because randomised controlled trials include selected patients populations that rarely represent the real situation ${ }^{35}$.

In conclusion, ACT seems to be better than PACT for compatibility with GINA in assessing control status in children. Probably, it is because older children have a longer recall period than younger ones( $<12 \mathrm{yrs})$. The better correlation of PAQLQ and ACT and better compability of PAQLQ and GINA in older children may also be related to this reason. Neverthless, the cut-off levels for PACT and ACT differ from study to study. This may be because diffent study populations, varying study designs, care settings and rate of patients with uncontrolled asthma. So, it would be better to use these tools for individual patients by comparing their own tests, instead of determining control status according to cut-off values, until large scale studies are performed to determine cut-off values of the tools for each population individually.

\section{REFERENCES}

1. Global Strategy for Asthma Management and Prevention (GINA). Available at https://ginasthma.org/wp-content/uploads/2020/04/GINA-2020-full-report_-final-_wms.pdf. Accessed on 6 May 2020.

2. Slob EM, Maitland-Van der Zee AH, Koppelman GH, Pijnenburg MW. Precision medicine in childhood asthma. Curr Opin Allergy Clin Immunol . Apr 2019;19(2):141-147. doi:10.1097/ACI.0000000000000517

3. National Asthma E, Prevention P. Expert Panel Report 3 (EPR-3): Guidelines for the Diagnosis and Management of Asthma-Summary Report 2007. J Allergy Clin Immunol . Nov 2007;120(5 Suppl):S94-138. doi:10.1016/j.jaci.2007.09.043

4. Sorkness CA, Lemanske RF, Jr., Mauger DT, et al. Long-term comparison of 3 controller regimens for mild-moderate persistent childhood asthma: the Pediatric Asthma Controller Trial. J Allergy Clin Immunol . Jan 2007;119(1):64-72. doi:10.1016/j.jaci.2006.09.042

5. Voorend-van Bergen S, Vaessen-Verberne AA, de Jongste JC, Pijnenburg MW. Asthma control questionnaires in the management of asthma in children: A review. Pediatr Pulmonol . Feb 2015;50(2):202-8. doi:10.1002/ppul.23098

6. Erkocoglu M, Akan A, Civelek E, Kan R, Azkur D, Kocabas CN. Consistency of GINA criteria and childhood asthma control test on the determination of asthma control. Pediatr Allergy Immunol . Feb 2012;23(1):34-9. doi:10.1111/j.1399-3038.2011.01232.x

7. Deschildre A, Pin I, El Abd K, et al. Asthma control assessment in a pediatric population: comparison between GINA/NAEPP guidelines, Childhood Asthma Control Test (C-ACT), and physician's rating. Allergy . Jun 2014;69(6):784-90. doi:10.1111/all.12402

8. Voorend-van Bergen S, Vaessen-Verberne AA, Landstra AM, et al. Monitoring childhood asthma: web-based diaries and the asthma control test. J Allergy Clin Immunol . Jun 2014;133(6):1599-605 e2. doi:10.1016/j.jaci.2013.10.005

9. Somashekar AR, Ramakrishnan KG. Evaluation of Asthma Control in Children Using Childhood- Asthma Control Test (C-ACT) and Asthma Therapy Assessment Questionnaire (ATAQ). Indian Pediatr . Sep 15 2017;54(9):746-748. doi:10.1007/s13312-017-1167-2

10. Koolen BB, Pijnenburg MW, Brackel HJ, et al. Comparing Global Initiative for Asthma (GINA) criteria with the Childhood Asthma Control Test (C-ACT) and Asthma Control Test (ACT). Eur Respir J . Sep 2011;38(3):561-6. doi:10.1183/09031936.00173710

11. Hahn YS. Measurements of fractional exhaled nitric oxide in pediatric asthma. Korean J Pediatr . Oct 2013;56(10):424-30. doi:10.3345/kjp.2013.56.10.424

12. Dweik RA, Boggs PB, Erzurum SC, et al. An official ATS clinical practice guideline: interpretation of exhaled nitric oxide levels (FENO) for clinical applications. Am J Respir Crit Care Med. Sep 1 
2011;184(5):602-15. doi:10.1164/rccm.9120-11ST

13. Juniper EF, Guyatt GH, Feeny DH, Ferrie PJ, Griffith LE, Townsend M. Measuring quality of life in children with asthma. Qual Life Res . Feb 1996;5(1):35-46. doi:10.1007/BF00435967

14. Bateman ED, Bousquet J, Keech ML, Busse WW, Clark TJ, Pedersen SE. The correlation between asthma control and health status: the GOAL study. Eur Respir J . Jan 2007;29(1):56-62. doi:10.1183/09031936.00128505

15. Miadich SA, Everhart RS, Borschuk AP, Winter MA, Fiese BH. Quality of Life in Children With Asthma: A Developmental Perspective. J Pediatr Psychol . Aug 2015;40(7):672-9. doi:10.1093/jpepsy/jsv002

16. Bernstein IL, Li JT, Bernstein DI, et al. Allergy diagnostic testing: an updated practice parameter. Ann Allergy Asthma Immunol . Mar 2008;100(3 Suppl 3):S1-148.

17. Sekerel BE, Soyer OU, Keskin O, et al. The reliability and validity of Turkish version of Childhood Asthma Control Test. Qual Life Res . May 2012;21(4):685-90. doi:10.1007/s11136-011-9970-z

18. Uysal MA, Mungan D, Yorgancioglu A, et al. The validation of the Turkish version of Asthma Control Test. Qual Life Res . Sep 2013;22(7):1773-9. doi:10.1007/s11136-012-0309-1

19. Liu AH, Zeiger R, Sorkness C, et al. Development and cross-sectional validation of the Childhood Asthma Control Test. J Allergy Clin Immunol . Apr 2007;119(4):817-25. doi:10.1016/j.jaci.2006.12.662

20. Schatz M, Sorkness CA, Li JT, et al. Asthma Control Test: reliability, validity, and responsiveness in patients not previously followed by asthma specialists. J Allergy Clin Immunol . Mar 2006;117(3):549-56. doi:10.1016/j.jaci.2006.01.011

21. Yuksel H, Yilmaz O, Kirmaz C, Eser E. Validity and reliability of the Turkish translation of the Pediatric Asthma Quality of Life Questionnaire. Turk J Pediatr . Mar-Apr 2009;51(2):154-60.

22. Khalili B, Boggs PB, Bahna SL. Reliability of a new hand-held device for the measurement of exhaled nitric oxide. Allergy . Oct 2007;62(10):1171-4. doi:10.1111/j.1398-9995.2007.01475.x

23. Standardization of Spirometry, 1994 Update. American Thoracic Society. Am J Respir Crit Care Med . Sep 1995;152(3):1107-36. doi:10.1164/ajrccm.152.3.7663792

24. Yung JA, Fuseini H, Newcomb DC. Hormones, sex, and asthma. Ann Allergy Asthma Immunol . May 2018;120(5):488-494. doi:10.1016/j.anai.2018.01.016

25. Reddel HK, Taylor DR, Bateman ED, et al. An official American Thoracic Society/European Respiratory Society statement: asthma control and exacerbations: standardizing endpoints for clinical asthma trials and clinical practice. Am J Respir Crit Care Med . Jul 1 2009;180(1):59-99. doi:10.1164/rccm.200801-060ST

26. Rosias PP, Dompeling E, Dentener MA, et al. Childhood asthma: exhaled markers of airway inflammation, asthma control score, and lung function tests. Pediatr Pulmonol . Aug 2004;38(2):107-14. doi:10.1002/ppul.20056

27. Senna G, Passalacqua G, Schiappoli M, Lombardi C, Wilcock L. Correlation among FEV, nitric oxide and asthma control test in newly diagnosed asthma. Allergy . Feb 2007;62(2):207-8. doi:10.1111/j.13989995.2006.01250.x

28. Tibosch M, de Ridder J, Landstra A, et al. Four of a kind: asthma control, FEV1, FeNO, and psychosocial problems in adolescents.Pediatr Pulmonol . Oct 2012;47(10):933-40. doi:10.1002/ppul.22514

29. Killian KJ, Watson R, Otis J, St Amand TA, O'Byrne PM. Symptom perception during acute bronchoconstriction. Am J Respir Crit Care Med . Aug 2000;162(2 Pt 1):490-6. doi:10.1164/ajrccm.162.2.9905079 
30. Rosi E, Stendardi L, Binazzi B, Scano G. Perception of airway obstruction and airway inflammation in asthma: a review. Lung . Sep-Oct 2006;184(5):251-8. doi:10.1007/s00408-005-2590-z

31. Karadeniz P, Ozdogan S, Ayyildiz-Emecen D, Oncul U. Asthma control test and pediatric asthma quality of life questionnaire association in children with poor asthma control. Turk J Pediatr . 2016;58(5):464-472. doi:10.24953/turkjped.2016.05.002

32. Netz M, Fedele DA, Sweenie R, Baker D, Light M, McQuaid EL. Asthma Management Responsibility, Control, and Quality of Life Among Emerging Adolescents. J Pediatr Psychol . Jan 1 2020;45(1):40-49. doi:10.1093/jpepsy/jsz069

33. Matsunaga NY, Ribeiro MA, Saad IA, Morcillo AM, Ribeiro JD, Toro AA. Evaluation of quality of life according to asthma control and asthma severity in children and adolescents. J Bras Pneumol . Nov-Dec 2015;41(6):502-8. doi:10.1590/S1806-37562015000000186

34. Banjari M, Kano Y, Almadani S, Basakran A, Al-Hindi M, Alahmadi T. The Relation between Asthma Control and Quality of Life in Children.Int J Pediatr . 2018;2018:6517329. doi:10.1155/2018/6517329

35. Sherman RE, Anderson SA, Dal Pan GJ, et al. Real-World Evidence - What Is It and What Can It Tell Us? N Engl J Med . Dec 8 2016;375(23):2293-2297. doi:10.1056/NEJMsb1609216

Table 1. Comparison of characteristics of the patients with well-controlled and not well-controlled asthma

\begin{tabular}{|c|c|c|c|}
\hline Characteristics & $\begin{array}{l}\text { Well-controlled asthma } \\
\mathrm{n}\left(\%^{*}\right) 192(84.2)\end{array}$ & $\begin{array}{l}\text { Not well-controlled } \\
\text { asthma } \mathrm{n}\left(\%^{*}\right) 36(15.8)\end{array}$ & $\mathrm{P}$ \\
\hline Male & $118(89.4)$ & $14(10.6)$ & 0.012 \\
\hline $\begin{array}{l}\text { Age (yr) (median, } \\
\text { IQR) }\end{array}$ & $10.5(8.3-12.5)$ & $12.2(9.6-14.4)$ & 0.005 \\
\hline $\begin{array}{l}\text { Duration of follow up } \\
\text { (yr) (median, IQR) }\end{array}$ & $2.1(1.0-5.1)$ & $3.3(1.5-6.4)$ & 0.180 \\
\hline Tobacco exposure & $113(85.6)$ & $19(14.4)$ & 0.498 \\
\hline $\begin{array}{l}\text { Aeroallergen } \\
\text { sensitisation }\end{array}$ & $99(90.0)$ & $11(10.0)$ & 0.021 \\
\hline Asthma therapy & & & 0.059 \\
\hline As needed SABA & $51(91.1)$ & $5(8.9)$ & \\
\hline ICS use & $127(83.1)$ & $26(16.9)$ & \\
\hline ICS monotherapy & $99(83.2)$ & $20(16.8)$ & \\
\hline LTRA monotherapy & $14(77.8)$ & $4(22.2)$ & \\
\hline ICS+LTRA & $16(94.2)$ & $1(5.8)$ & \\
\hline ICS+LABA & $12(70.6)$ & $5(29.4)$ & \\
\hline ICS+LABA+LTRA & $0(0.0)$ & $1(100)$ & \\
\hline Asthma severity & & & 0.167 \\
\hline İntermittent & $53(89.8)$ & $6(10.2)$ & \\
\hline Mild persistent & $95(81.2)$ & $22(18.8)$ & \\
\hline Moderate persisitent & $33(94.3)$ & $2(5.7)$ & \\
\hline Severe persistent & $11(64.7)$ & $6(35.3)$ & \\
\hline $\begin{array}{l}\text { Allerjic rhinitis } \\
\text { coexistent }\end{array}$ & $81(85.3)$ & $14(14.7)$ & 0.695 \\
\hline FeNO (ppb) & $19(14-28)$ & $19(16-26)$ & 0.654 \\
\hline $\mathrm{PACT}$ & $23(19-26)$ & $18(13.5-21)$ & $<0.001$ \\
\hline $\mathrm{ACT}$ & $22.5(19.25-24.75)$ & $15(14-19)$ & $<0.001$ \\
\hline PAQLQ (median, IQR) & $6.1(5.2-6.6)$ & $4.8(3.9-5.6)$ & $<0.001$ \\
\hline Symptoms & $5.4(4.6-6.6)$ & $3.8(2.8-5.2)$ & $<0.001$ \\
\hline Emotional functions & $6.2(5.4-6.7)$ & $4.6(3.8-5.4)$ & $<0.001$ \\
\hline
\end{tabular}




\begin{tabular}{llll}
\hline Characteristics & $\begin{array}{l}\text { Well-controlled asthma } \\
\mathrm{n}\left(\%^{*}\right) 192(84.2)\end{array}$ & $\begin{array}{l}\text { Not well-controlled } \\
\text { asthma } \mathrm{n}\left(\%^{*}\right) 36(15.8)\end{array}$ & $\mathrm{P}$ \\
\hline $\begin{array}{l}\text { Activity limitation } \\
\text { Spirometry (median, }\end{array}$ & $6.4(5.2-7.0)$ & $5.5(4.5-6.2)$ & $\mathbf{0 . 0 0 1}$ \\
IQR) & & & \\
$\mathrm{FEV}_{1}$ (expected \%) & $93(87-103)$ & $94(83-103)$ & 0.757 \\
$\mathrm{FEV}_{1} /$ FVC (ratio) & $0.99(0.93-1.05)$ & $0.97(0.94-1.05)$ & 0.724 \\
$\mathrm{FEF}_{25-75}$ (expected \%) & $92(79-112)$ & $88(79-106)$ & 0.485 \\
\hline
\end{tabular}

*Percents of rows

yr: year, IQR: interquartile range, SABA: short acting beta-2 agonist, ICS: inhaled corticosteroid, LTRA: leukotriene receptor antagonist, LABA: long acting beta-2 agonist, FeNO: fractional exhaled nitric oxide, $\mathrm{ACT} / \mathrm{pACT}$ : asthma control test/pediatric asthma control test, $\mathrm{FEV}_{1}$ : forced expiratory volüme in one second, $\mathrm{FEV}_{1} / \mathrm{FVC}$ : the ratio of "forced expiratory volüme in one second" to "forced vital capacity", $\mathrm{FEF}_{25-75}$ : forced expiratory flow at $25 \%$ to $75 \%$ of forced vital capacity.

Table 2. Compatibility of the tests with GINA criteria

\begin{tabular}{llllll}
\hline & Cut off level & Compatibility with GINA & Compatibility with GINA & $\chi$ & $\mathrm{p}$ \\
\hline & & Not well-controlled asthma $\mathrm{n}(\%)^{*}$ & Well-controlled asthma $\mathrm{n}(\%)^{*}$ & & \\
FeNO & $>35 \mathrm{ppb}$ & $2(6.1)$ & $162(83.1)$ & -0.106 & 0.109 \\
$\mathrm{FeNO}$ & $>20 \mathrm{ppb}$ & $15(14.4)$ & $96(84.2)$ & -0.014 & 0.779 \\
$\mathrm{PACT}$ & $<22$ & $15(23.1)$ & $78(97.5)$ & $\mathbf{0 . 2 2 1}$ & $<\mathbf{0 . 0 0 1}$ \\
$\mathrm{ACT}$ & $<21$ & $17(48.6)$ & $45(95.8)$ & $\mathbf{0 . 4 7 3}$ & $<\mathbf{0 . 0 0 1}$ \\
$\mathrm{PAQLQ}$ & $<5.9$ & $29(27.9)$ & $110(94.8)$ & $\mathbf{0 . 1 5 0}$ & $<\mathbf{0 . 0 0 1}$ \\
$\mathrm{FEV}_{1}$ & $<80 \%$ & $6(27.3)$ & $160(85.6)$ & 0.105 & 0.118 \\
$\mathrm{FEV}_{1} / \mathrm{FVC}$ & $<0.80$ & $0(0.0)$ & $173(84.0)$ & -0.027 & 0.450 \\
$\mathrm{FEF}_{25-75}$ & $<80 \%$ & $9(15.5)$ & $127(84.1)$ & -0.004 & 0.947 \\
\hline
\end{tabular}

*Percents of row.

kappa

FeNO: fractional exhaled nitric oxide, $\mathrm{ACT} / \mathrm{pACT}$ : asthma control test/pediatric asthma control test, $\mathrm{FEV}_{1}$ : forced expiratory volume in one second, $\mathrm{FEV}_{1} / \mathrm{FVC}$ : the ratio of "forced expiratory volume in one second" to "forced vital capacity", $\mathrm{FEF}_{25-75}$ : forced expiratory flow at $25 \%$ to $75 \%$ of forced vital capacity.

Table 3. Pediatric Asthma Control Test (PACT) with various cut-off points compared with GINA criteria for assessing "not-well controlled" asthma in 145 patients

\begin{tabular}{llllllll}
\hline $\begin{array}{l}\text { Cut-off } \\
\text { points }\end{array}$ & $\begin{array}{l}\text { Sensitivity } \\
\%\end{array}$ & Specifity $\%$ & PPV $\%$ & NPV $\%$ & $\begin{array}{l}\text { Correctly } \\
\text { classified } \%\end{array}$ & $x$ & p \\
\hline$<17$ & 84.4 & 47.1 & 28.6 & 92.3 & 80.0 & 0.245 & 0.002 \\
$<18$ & 77.3 & 58.8 & 25.6 & 93.4 & 75.2 & 0.232 & 0.002 \\
$<19$ & 73.4 & 64.7 & 24.4 & 94.0 & 72.4 & 0.223 & 0.001 \\
$<20$ & 69.5 & 64.7 & 22 & 93.7 & 69.0 & 0.186 & 0.005 \\
$<\mathbf{2 1}$ & $\mathbf{6 0 . 9}$ & $\mathbf{8 8 . 2}$ & $\mathbf{2 3 . 1}$ & $\mathbf{9 7 . 5}$ & $\mathbf{6 4 . 1}$ & $\mathbf{0 . 2 2 1}$ & $<\mathbf{0 . 0 0 1}$ \\
$<22$ & 52.3 & 94.2 & 20.8 & 98.5 & 57.2 & 0.184 & $<0.001$ \\
$<23$ & 44.5 & 94.1 & 18.4 & 98.3 & 50.3 & 0.139 & 0.002
\end{tabular}




\begin{tabular}{llllllll}
\hline $\begin{array}{l}\text { Cut-off } \\
\text { points }\end{array}$ & $\begin{array}{l}\text { Sensitivity } \\
\%\end{array}$ & Specifity $\%$ & PPV $\%$ & NPV $\%$ & $\begin{array}{l}\text { Correctly } \\
\text { classified } \%\end{array}$ & $x$ & $\mathrm{p}$ \\
\hline$<24$ & 35.2 & 100 & 17.0 & 100 & 42.8 & 0.113 & 0.003 \\
\hline
\end{tabular}

PPV: positive predictive value; NPV: negative predictive value

kappa

Table 4. Asthma Control Test (ACT) with various cut-off points compared with GINA criteria for assessing "not-well controlled" asthma in 83 patients

\begin{tabular}{llllllll}
\hline $\begin{array}{l}\text { Cut-off } \\
\text { points }\end{array}$ & $\begin{array}{l}\text { Sensitivity } \\
\%\end{array}$ & Specifity $\%$ & PPV $\%$ & NPV $\%$ & $\begin{array}{l}\text { Correctly } \\
\text { classified } \%\end{array}$ & x & p \\
\hline$<17$ & 89.1 & 68.4 & 65.0 & 90.5 & 84.3 & 0.564 & $<0.001$ \\
$<18$ & 81.2 & 73.7 & 53.8 & 91.2 & 79.5 & 0.486 & $<0.001$ \\
$<19$ & 75.0 & 78.9 & 48.4 & 92.3 & 75.9 & 0.441 & $<0.001$ \\
$<\mathbf{2 0}$ & $\mathbf{7 1 . 9}$ & $\mathbf{8 9 . 5}$ & $\mathbf{4 8 . 6}$ & $\mathbf{9 5 . 8}$ & $\mathbf{7 5 . 9}$ & $\mathbf{0 . 4 7 3}$ & $<0.001$ \\
$<21$ & 65.6 & 89.4 & 43.6 & 95.5 & 71.1 & 0.402 & $<0.001$ \\
$<22$ & 50.0 & 94.7 & 36.0 & 97.0 & 60.2 & 0.284 & $<0.001$ \\
$<23$ & 39.1 & 94.7 & 31.6 & 96.2 & 51.8 & 0.198 & 0.005 \\
$<24$ & 25 & 94.7 & 27.3 & 94.1 & 41.0 & 0.106 & 0.061 \\
\hline
\end{tabular}

PPV: positive predictive value; NPV: negative predictive value kappa 